\title{
Development of preschool social emotional inventory for preschoolers: a preliminary study
}

\author{
Goh Wah Im ${ }^{1}$, Yeo Kee Jiar², Rohaya Bt. Talib ${ }^{3}$ \\ ${ }^{1}$ Department of Education, Institut Pendidikan Guru Kampus Temenggong Ibrahim, Malaysia \\ ${ }^{2,3}$ Faculty of Education, Universiti Teknologi Malaysia, Malaysia
}

\begin{tabular}{l}
\hline Article Info \\
\hline Article history: \\
Received Jan 17, 2019 \\
Revised Feb 21, 2019 \\
Accepted Feb 28, 2019 \\
\hline
\end{tabular}

Keywords:

Instrument

Inventory

Preschool

Social emotional competencies

Social emotional learning

\begin{abstract}
Social-emotional competencies have been established as important predictors in children's mental health, school readiness and academic success. Age and developmentally appropriate screening for preschool children is important for early detection of developmental delays and early intervention. The purpose of this study is to measure preschool children's social emotional competencies (SEC) based on the Malaysian context using the Preschool Social Emotional Competency Inventory (P-SECI) developed to provide parents, teachers and childcare professionals with a standardized, normreferenced, reliable and valid instrument. A pool of 50 items was created for P-SECI, representing eight clusters of social emotional competencies in children: self-awareness, social awareness, self-management, relationship management, attachment, communication, responsible decision making and pro-social skills. This pilot study involved two public Annex preschools in Johor Bahru, purposely selected with 49 preschool children as respondents. Results showed that P-SECI has a high reliability index (Alpha CronbachTeachers .98 and Parents .95). Initial findings also showed that Teachers and Parents differ in their evaluation of their children's SEC according to age and gender. But for the age criteria, the mean difference is slightly wider in comparison to gender. Therefore, P-SECI is relevant in predicting children's mental health, school readiness and academic achievement. Results from the study also showed that the inventory holds promise as a reliable and valid instrument to evaluate SEC in young children according to the Malaysian context.
\end{abstract}

Copyright (C) 2019 Institute of Advanced Engineering and Science. All rights reserved.

\section{Corresponding Author:}

Goh Wah Im

Institut Pendidikan Guru Kampus Temenggong Ibrahim,

Jalan Datin Halimah,

80350 Johor Bahru, Johor, Malaysia.

Email: gowimp@yahoo.com

\section{INTRODUCTION}

The development of social-emotional competence (SEC) is an important foundation for young children to achieve success in schools and in later lives. New empirical research has provided a new perspective on the importance of social-emotional competence to school readiness. A number of researchers have shown that children who enter kindergarten with more positive profiles of social-emotional competence have not only more success in developing positive attitudes about school and successful early adjustment to school, but also improved grades and achievement [1]-[3]. A child with poor SEC is at risk of having poor relationships with peers, behavioural problems, underachievement in academics or developing physical and mental health problems. In a recent review of studies on SEC, the development of children's social, emotional and behavioural skills have been linked to greater educational success, improvements in 
behaviour, increased inclusion, improved learning, greater social cohesion, and improvements in mental health [4], [5].

Currently there are 626,206 preschool children attending some form of early childhood program, either publicly run by the government authorities or privately run by companies or individuals [6]. Given the increasing awareness of the importance of SEC to adjustment during the preschool years and to success during the transition to formal schooling [7], there is an increasing need for measures of social competence that are brief, easy-to-use, and have utility in assessing the construct in preschoolers. There is a lack of systematic assessment procedures and instruments for early detection of children with poor SEC in Malaysia which hinders the possibility of early intervention and treatment to prevent future problems. Presently, there is no specific instrument recommended by the Education Ministry for schools to assess children's SEC. Teachers need to understand children's development of SEC and aspects of the construct in order to provide information for interventions, targeting young children at risk for poor outcomes due to deficits in social competence or related behavioural problems [7], [8]. There are some available instruments of popular scales from the United States and United Kingdom used by researchers when carrying out their research in the schools such as DESSA, DECA and SCQ. These instruments are specific to the cultures of their origin and do not take into account our local cultural factors. Therefore, the evaluation of social-emotional development risks the biases of clinical appraisal or the biases of the cultural differences embedded in instruments devised elsewhere [9]. Culturally appropriate scales are necessary since the way parents relate to children, the amount of freedom allowed, the expectations they have, among other events differ from one culture to another. Consequently standards of social adjustment vary with the cultural norms by which they are judged [10]. Appropriate assessment devices, therefore, must abide with cultural norms and this appears to be a very important factor in assessing the child's scholastic potential. Hence, the purpose of this pilot study was to do a feasibility test on P-SECI, an instrument to provide parents, teachers and childcare professionals with a standardized, norm-referenced, reliable and valid instrument which is easy to use to evaluate children's SEC according to the Malaysian context to detect developmental delays for preschool children age 4 to 6 years old.

SEC is a child's ability to experience, regulate and express emotions, to form close and secure interpersonal relationships with people around him, and to explore his environment and learn, all in the context of family, community, and culture. It is a complex term relating to various emotional literacy and prosocial skills which allows the child to function in his surroundings. According to Mayer and Ciarrochi, SEC is a combination of emotional intellect, social effectiveness, and, perhaps, emotional intelligence itself might be represented by the term socio-emotional effectiveness - 'an individual's capacity to navigate the social world in an effective manner, accomplishing his or her goals as needed [11].

In recent years, research has suggested that there is a strong link between young children's socioemotional competence and their chances of early school success [12], [13], [3]. A well-planned and wellimplemented social-emotional programme can positively affect academic outcomes [1]. Social-emotional learning (SEL) was first introduced in 1994 as a conceptual framework incorporating SEL and emotional competence. CASEL (Collaborative to Advance Social and Emotional Learning), the world's leading organisation promoting integrated academic, social, and emotional learning for all children in preschool through high school identifies SEL as competencies or skills in "identifying and labeling feelings, expressing feelings, assessing the intensity of feelings, managing feelings, delaying gratification, controlling impulses, and reducing stress". CASEL established five interrelated sets of cognitive, affective and behavioral competencies as shown in Figure 1. The definitions of the five SEC clusters for students are:

a. Self-awareness is the ability to accurately recognize one's emotions and thoughts and their influence on one's behavior. It includes accurately assessing one's strengths, weaknesses and limitations, as well as possessing a well-grounded sense of confidence and optimism.

b. Self-management is the ability to regulate one's emotions, thoughts, and behaviors effectively in different situations one encounters. It includes managing tension and stress, controlling one's impulses, motivating oneself, setting and working towards achieving one's personal and academic goals.

c. Social awareness is the ability to take the perspective of others, to empathize with others from diverse backgrounds and cultures, to understand social and ethical norms for the right behavior, to recognize family, school, and community resources and support.

d. Relationship management skills is the ability to establish and maintain healthy and rewarding relationships with diverse individuals and groups. It includes interpersonal skill, interacting with others, listening actively, cooperating, resisting inappropriate social pressure, negotiating conflict constructively, and seeking and offering help when needed. 
e. Responsible decision making is the ability to make constructive and respectful choices about one's personal behavior and social interactions based on consideration of ethical standards and norms, safety concerns, social norms, realistic evaluation of consequences of various actions, and the wellbeing of self and others.

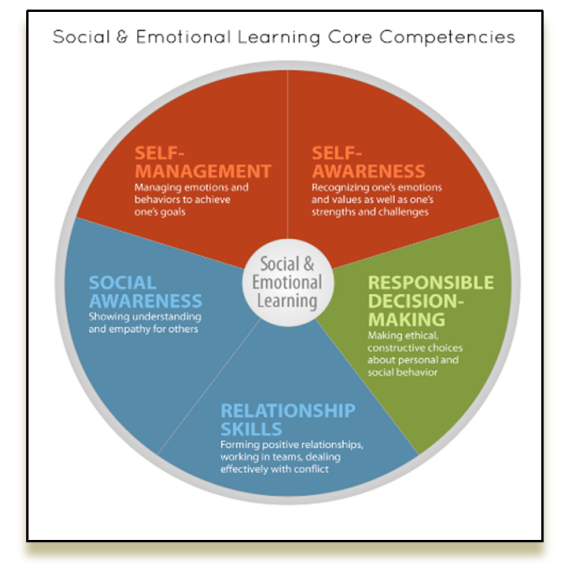

Figure 1. CASEL 5 SEC clusters

(Source: http://www.casel.org/social-and-emotional-learning/core-competencies/)

In order to make P-SECI relevant and developmentally appropriate to young children, all 5 of the above SEC clusters identified by CASEL were included in the items selection but another 3 more clusters were added by the researcher based on social emotional theories, child development and learning theories. These 3 new clusters were attachment, communication skills and prosocial skills which are important clusters of SEC which needed to be incorporated since young children's needs and social-emotional development are different from those of older children and adults.

a. Attachment is the bonding which is created when a child's experiences with the parents/primary caregivers that are reliable, predictable and accessible during their care in the past. The quality of attachment is determined by the child's willingness to engage and benefit from social interactions. The basis for trust in relationships with others would develop from early attachments. This relationship builds the ability to form close relationships with others throughout their life [14], [15]. This is also stated Erikson's Psychosocial Theory in Stage 1: Trust vs Mistrust. If an infant's physical and emotional needs are met in a consistent and caring way, he learns that his mother or caregiver can be counted on and he develops an attitude of trust in people. If his needs are not met, he may become fearful and learns not to trust the people around him. An infant must first form a trusting relationship with the parents/caregiver, otherwise a sense of mistrust will develop. If the child has a secure attachment, it is more likely that he would be willing to interact with others outside the family as it favors exploratory behaviors increasing the likelihood of social interactions. Ainsworth identified three different types of attachment: secure, ambivalent and avoidance) each of them leading to different types of behavior in the children [16]. Waters et al. concluded that the quality of attachment would predict competence and acceptance in the peer group [17]. Lieberman et al. found that the social competence of the children was related to the quality of the attachment between mother and children, and the amount of experience that the child had had with peers and also established that father availability was related to children having less conflict with their friends [18]. Inconsistent or rejecting parents are more likely to create insecure attachments and this could have disastrous consequences for children's social relationships with peers [19], [15].

b. Communication skills reflect children's ability to properly interact with other children and adults using interpersonal skills. It is an important skill especially for young children with limited amount of vocabulary and find difficulty in verbalising their emotions and thoughts which can be too abstract and overwhelming to them. When adults talk with children about emotions, it helps children to understand their emotions and others' emotions as well. This helps children have more positive relationships with their peers leading to a greater ability to regulate their emotions and behaviour [20]. Communication skills can be best evaluated in play settings where children establish and maintain friendships [21]. With age, their play patterns become more complex and sophisticated and interaction and communication

Int. J. Eval. \& Res. Educ. Vol. 8, No. 1, March 2019: 158 - 164 
form the basis for intricate play scenarios. Children with poor friendship skills are rejected by their peers and as a consequence lack the opportunity to develop their social skills [22]. These children are at risk for developing both internalizing and externalizing disorders [23]. Children's ability to maintain interactions in larger groups evolves with time. By 5-years old, children are able to participate in cooperative play where they exchange ideas over play scenarios, and even attribute roles to children involved. Cooperative play stems from children understands of reciprocity as the basis of building and maintaining friendships [24].

c. Prosocial skills include a wide range of voluntary actions or behaviours directed at other people's benefit such as sharing toys and other objects, turn-taking, giving and asking for help [25]. Children low on prosocial behavior are rejected by their peers, are often aggressive and exhibit behaviors which put them at risk for externalizing disorders [26], [27] . Until the age of 5, most children need to be reminded to share, help or wait for their turn during a game but once these rules are internalised, most children tend to exhibit these behaviors without adult prompting [28] and also showing signs of lesser egocentricity, more interactions with their peers increasing their prosocial skills.

\section{RESEARCH METHOD}

This pilot study employed a survey design to collect data using P-SECI. The total number of preschool children included in this study were $\mathrm{N}=49$ from two public preschools in the town of Johor Bahru. These 2 public preschools are annexed to a national type primary school catering for parents from the middle and lower income groups and were purposely selected because of the homogenous characteristics (close proximity and similarities of the school, teachers, parents and children profiles). For feasibility and pilot studies the sample size recommended is 30 [29]. The sample characteristics for each group are shown in Table 1.

Table 1. Distribution of participants according to age group, gender and race

\begin{tabular}{cccccc}
\hline \multicolumn{2}{c}{ Age group } & Number of & \multicolumn{2}{c}{ Gender } & Race \\
5 years & 6 years & participants & Male & Female & \\
\hline 17 & 32 & 49 & 18 & 31 & Malays \\
\hline
\end{tabular}

An initial pool of 50 items was generated based on theories of child development, SEC, SocialEmotional Learning (SEL) and emotional intelligence. P-SECI was adopted and adapted from instruments used by US researchers; Devereux Student Strengths Assessment (DESSA), Ages and Stages Questionnaires: Social-Emotional (ASQ: SE), Strengths and Difficulties Questionnaire (SDQ) to make it more relevant to the Malaysian context. P-SECI contains pool of 50 items representing eight clusters of SEC which are selfawareness (SFA), social awareness (SOA), self-management (SFM), relationship management (RMT), attachment (ATM), communication (COM), pro-social skills (PRS) and responsible decision making (RDM). These items were subjected to content validated by a group of 6 experts from various fields of educational psychology, preschool education, language and psychometrics. as recommended by the Standards for Educational and Psychological Testing (American Educational Research Association). A four point Likert scale was used to check on the user's specific response (1-Never, 2-Rarely, 3- Occasionally, 4-Frequently). The final version of P-SECI was able to represent all the clusters of SEC as shown in Table 2 with all the items randomly placed in the inventory.

Table 2. Distribution of items according to 8 SEC clusters in the P-SECI

\begin{tabular}{llll}
\hline Coding & SEC Cluster & Item No. & Total \\
\hline SFA & Self-Awareness & $1,20,21,22,34,40$ & 5 \\
SOA & Social Awareness & $4,7,8,24,27$ & 6 \\
SFM & Self-Management & $3,6,11,13,23,31,48,49$ & 8 \\
RMT & Relationship Management & $25,26,30,36,42,43,50$ & 7 \\
COM & Communication Skills & $2,15,28,29,45$ & 5 \\
PRS & Prosocial Skills & $10,14,16,18,38,39$ & 6 \\
ATM & Attachment & $5,33,35,41,44,47$ & 5 \\
RDM & Relationship Decision Making & $9,12,17,19,32,37,46$ & 8 \\
Total Items & & 50 \\
\hline
\end{tabular}

A group appointment was set with teachers and parents during the preschools' Open Day to give a brief explanation of the purposes and aims of the research, followed by a discussion on the clarity, relevance

Development of preschool social emotional inventory for preschoolers: a preliminary study (Goh Wah Im) 
and wording of the inventory. They were then asked to fill the inventory and to hand in once they completed the task. The data collected were run using SPSS and analysed using descriptive statistics.

\section{RESULTS AND DISCUSSION}

Reliability is established through the data collected and analyzed using SPSS (Statistical Package for Social Sciences). The reliability coefficient (alpha Cronbach) $r$ values ranged between .98 for Teachers and .95 for Parents. Differences between Teachers and Parents reliability indices showed a very small value of .03. Table 3 and Table 4 show the analysis of mean of P-SECI according to age and gender respectively.

Table 3. Mean of P-SECI on age

\begin{tabular}{cccccc}
\hline & \multicolumn{3}{c}{ Table 3. Mean of P-SECI on age } \\
Age & N & Mean & $\begin{array}{c}\text { Standard } \\
\text { Deviation }\end{array}$ & Mean & $\begin{array}{c}\text { Standard } \\
\text { Deviation }\end{array}$ \\
\hline 5 years & 17 & 2.98 & .20 & 3.15 & .34 \\
6 years & 32 & 3.36 & .54 & 3.13 & .43 \\
Total & 49 & 3.27 & .51 & 3.13 & .41 \\
\hline
\end{tabular}

\begin{tabular}{cccccc}
\multicolumn{4}{c}{ Table 4. Mean of P-SECI on gender } \\
\hline Gender & $\mathrm{N}$ & Mean & $\begin{array}{c}\text { Ttandard } \\
\text { Deviation }\end{array}$ & Mean & $\begin{array}{c}\text { Ptandard } \\
\text { Deviation }\end{array}$ \\
\hline Male & 18 & 3.16 & .53 & 3.18 & .40 \\
Female & 31 & 3.33 & .49 & 3.11 & .41 \\
Total & 49 & 3.27 & .51 & 3.13 & .41 \\
\hline
\end{tabular}

Initial findings showed that teachers and parents differ in their evaluation of their children's SEC according to age and gender but for age, the mean differ is slightly larger compared to gender. Further research carried out on results of differences in age and gender. Initial findings indicated that P-SECI is relevant in predicting children's mental health, school readiness and academic success through analyzing the results of their social emotional competencies. Results from the study also showed that the inventory holds promise as a reliable and valid measure of social emotional competencies in young children for the Malaysian context.

P-SECI has a number of potential uses in practical situations. It was not designed as a diagnostic instrument in the sense of fitting medical settings but it can provide information that many practitioners in early childhood settings, schools and home or clinical environments may find useful as it is easy and quick to administer. Knowledge of the child's level of social-emotional development and competencies may aid parents, teachers and day-care personnel in understanding the child's behavior with other children or adults and also to find the ways to help them through shaping and early intervention. It also helps parents and teachers in understanding children at risk for future adaptive and academic problems and to plan programs of intervention to prevent future behavioural problems in school or in later life.

However, there is a need to further evaluate this instrument with further validation studies as this is only a feasibility study. Another shortcoming of this research is the fact that data on only one race was available but in future studies other races could be included, as well as different types of preschools using different medium of instruction and privately or publicly run. Future studies on P-SECI can be made in another possible area of research on characteristics of the social-emotional development of the child at age five as a predictor of later development outcomes and to what extent preschool measurements of SEC during the last year in preschool are predictive of the children's school performance in the Primary 1.

\section{CONCLUSION}

This is a first attempt to develop a screening instrument according to the Malaysian context to predict SEC and mental health problems in young children which may jeopardise their academic achievement and school readiness. A consistent longitudinal evaluation of young children is needed to prevent mental health problems and school maladjustment which may lead to more serious social problems in later years. It must be stated that the aim of screening is not simply labelling children as deficient in acquiring certain abilities, but rather promoting an early detection and intervention program to ensure children's wellbeing and success.

Int. J. Eval. \& Res. Educ. Vol. 8, No. 1, March 2019: 158 - 164 


\section{ACKNOWLEDGEMENTS}

We would like to thank the headmasters, preschool teachers and parents for their kind cooperation and assistance in this research. We would also like to show our gratitude to the Ministry of Education and the Johor Bahru District Education Office for granting us permission to carry our research in the 2 public preschools.

\section{REFERENCES}

[1] Zins, J. E, Weissberg, R. P, Wang, M. C., and Walberg, H. J., "Building academic success on social and emotional learning: What does the research say?," Teachers College Press, New York, 2004.

[2] Magdalena, S. M., "Social and emotional competence-predictors of school adjustment," Procedia-Social and Behavioral Sciences, vol. 76, pp. 29-33, Apr 2013.

[3] Darling-Churchill, K. E., Lippman, L., "Early childhood social and emotional development: Advancing the field of measurement," Journal of Applied Developmental Psychology, vol. 45, pp. 1-7, Jul 2016.

[4] Weare, K., Gray, G., "What works in developing children's emotional and social competence and wellbeing?," Department for Education and Skills, London, Jul 2003.

[5] Lancaster, G. A., Dodd, S., Williamson, P. R., "Design and analysis of pilot studies: recommendations for good practice," Journal of evaluation in clinical practice, vol. 10(2), pp. 307-12, May 2004.

[6] Ministry of Education, "Quick Facts 2017: Malaysia Educational Statistics," Kuala Lumpur: Educational Research and Planning Division, MOE, [Online] Availabe: https://www.moe.gov.my/images/Terbitan/Bukuinformasi/QUICK-FACTS-2017/20170809_QUICK-FACTS_2017_FINAL5_interactive.pdf, 2017

[7] Denham, S. A., "Social-emotional competence as support for school readiness: What is it and how do we assess it?," Early education and development, vol. 17(1), pp. 57-89, Jan 2006.

[8] Campbell, S. B., Denham, S. A., Howarth, G. Z, Jones, S. M., Whittaker, J. V., Williford, A. P., Willoughby, M. T., Yudron, M., Darling-Churchill, K., "Commentary on the review of measures of early childhood social and emotional development: Conceptualization, critique, and recommendations," Journal of Applied Developmental Psychology, vol. 45, pp. 19-41, Jul 2016.

[9] Aguiar, R., Sánchez, P., Satterly, D., "A Social Development Assessment Scale for Mexican children. Revista Electrónica de Investigación Educativa," vol. 7(1), pp. 1-27, 2005.

[10] Coll, C. G., Magnuson, K., "The psychological experience of immigration: A developmental perspective. Immigration and the family: Research and policy on US immigrants," pp. 91-131, 1997.

[11] Mayer, J. D., Ciarrochi, J., "Clarifying concepts related to emotional intelligence: A proposed glossary. Emotional intelligence and everyday life," pp. 261-7, 2006.

[12] Denham, S. A., Bassett, H. H., Zinsser, K., Wyatt, T. M., "How preschoolers' social-emotional learning predicts their early school success: Developing theory-promoting, competency-based assessments," Infant and Child Development, vol. 23(4), pp. 426-54, Jul 2014.

[13] Raver, C., "Young children's emotional development and school readiness," Social policy report, vol. 16(3), pp. 3-19, 2003.

[14] Denham, S. A., Wyatt, T. M., Bassett, H. H., Echeverria, D., Knox, S. S., "Assessing social-emotional development in children from a longitudinal perspective," Journal of Epidemiology \& Community Health, vol. 63(1), pp. 37-52, Jan 2009.

[15] Mikulincer, M., Shaver, P. R., "An attachment perspective on psychopathology," World Psychiatry, vol. 11(1), pp. 11-5, Feb 2012.

[16] Ainsworth, M. S., "Infant-mother attachment," American psychologist, vol. 34(10), pp. 932, Oct 1979.

[17] Waters, E., Wippman, J., Sroufe, L. A., "Attachment, positive affect, and competence in the peer group: Two studies in construct validation," Child development, pp. 821-9, Sep 1979.

[18] Lieberman, M., Doyle, A. B., Markiewicz, D., "Developmental patterns in security of attachment to mother and father in late childhood and early adolescence: Associations with peer relations," Child development, vol. 70(1), pp. 202-13, Jan 1999.

[19] Cohn, D. A., "Child-mother attachment of six-year-olds and social competence at school," Child development, vol. 61(1), pp. 152-62, Feb 1990

[20] Test, J. E., Cunningham, D. D., Lee, A. C., "Talking with Young Children: How Teachers Encourage Learning. Dimensions of early childhood,"vol. 38(3), pp. 3-14, 2010.

[21] McLaughlin, T., Aspden, K., Clarke, L., Pierce, G., Clarkin-Phillips, J., Hedges, H., Weisz-Koves, T., Cooper, M., Lovatt, D., McChesney, J., Mitchell, L., "How do teachers support children's social-emotional competence? Strategies for teachers," Early Childhood Folio, vol. 21(2), pp. 21-27, 2017.

[22] Gagnon, S. G., Nagle, R. J., "Relationships between peer interactive play and social competence in at-risk preschool children. Psychology in the Schools," vol. 41(2), pp. 173-89, Feb 2004.

[23] Dennis, T. A., Brotman, L. M., Huang, K. Y., Gouley, K. K., "Effortful control, social competence, and adjustment problems in children at risk for psychopathology," Journal of Clinical Child and Adolescent Psychology, vol. 36(3), pp. 442-54, Jul 2007.

[24] Rubin, K. H., Coplan, R., Chen, X., Bowker, J. C., McDonald, K. and Heverly-Fitt, S., "Peer relationships in childhood," In M. H. Bornstein and M. E. Lamb (et al.), Developmental Science: An Advanced Textbook. (7th edition), Psychology Press, pp. 591-649, New York, Jan 2015. 
[25] Warnes, E. D., Sheridan, S. M., Geske, J., Warnes, W. A., "A contextual approach to the assessment of social skills: Identifying meaningful behaviors for social competence," Psychology in the Schools, vol. 42(2), pp. 173-87, Feb 2005.

[26] Sebanc, A. M., "The friendship features of preschool children: Links with prosocial behavior and aggression," Social Development, vol. 12 (2), pp. 249-68, May 2003.

[27] Flook, L., Goldberg, S. B., Pinger, L., Davidson, R. J., "Promoting prosocial behavior and self-regulatory skills in preschool children through a mindfulness-based kindness curriculum," Developmental Psychology, vol. 51(1), pp. 44, Jan 2015.

[28] Strayer, J., Roberts, W., "Children's anger, emotional expressiveness, and empathy: Relations with parents' empathy, emotional expressiveness, and parenting practices," Social development, vol. 13(2), pp. 229-54, May 2004.

[29] Lancaster, G. A., Dodd, S., Williamson, P. R., "Design and analysis of pilot studies: recommendations for good practice," Journal of evaluation in clinical practice, vol. 10(2), pp. 307-12, May 2004.

\section{BIOGRAPHIES OF AUTHORS}
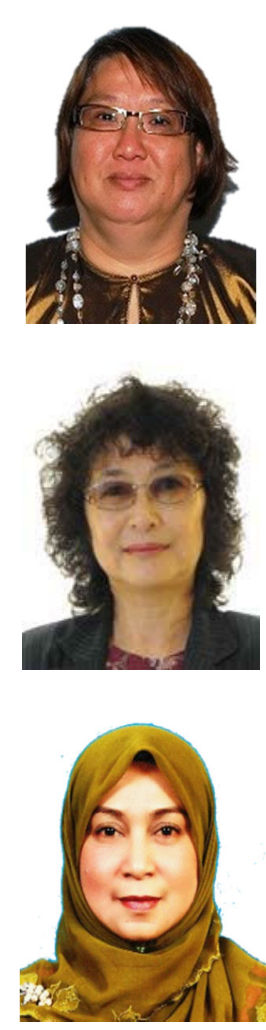

Goh Wah Im is a senior lecturer attached to the Department of Education, Institut Pendidikan Guru Kampus Temenggong Ibrahim, Johor, Malaysia. Her expertise is in the field of early childhood education (ECE) and has lectured a number of courses in the various educational fields to teacher trainees in both the local degree and overseas twinning programme. She has vast experience and wide involvement in the field of ECE, working with the Curriculum Development Centre in the Ministry of Education (MOE) in drafting and revising the national preschool curriculum, speaker and facilitator for the MOE's ECE Unit on early childhood and preschool education and curriculum. She was also involved in writing MOE's preschool teaching modules and guidebooks.

Professor Dr. Yeo Kee Jiar is a lecturer attached to the School of Education, Universiti Teknologi Malaysia, Johor, Malaysia. With her vast experience and involvement in the field of education, her expertise and interest covers a wide scope which includes educational psychology, early childhood education, and special education and Malay language. Among her notable involvement includes a few national level projects for research and consultation, as Munsyi Dewan under Dewan Bahasa dan Pustaka (Malay for The Institute of Language and Literature), publications in indexed journals as well as books, book chapters, and monographs. She has been a speaker and facilitator in many workshops and conferences centred on her field of specialisation and interest

Dr. Rohaya Talib is a senior lecturer in the Department of Educational Foundation and Social Science, Faculty of Education, Universiti Teknologi Malaysia, Johor, Malaysia. A respected academician with over 21 years of teaching and research experience.Her areas of expertise and interest are measurement and evaluation in education, scaling and instrumentation, quantitative statistical analysis, supervision in education and research methodology. She holds several academic and administrative positions in the university. She is involved in several research projects and innovations in education. She is also a sought after speaker and facilitator for workshops and courses in her field of specialization in measurement and evalution. Currently she is the coordinator of the measurement and evaluation programme for the Faculty of Education. 